\title{
The Technology Is Enemy for Me at the Moment: How Smart Home Technologies Assert Control Beyond Intent
}

\author{
Nils Ehrenberg \\ nils.ehrenberg@aalto.fi \\ Aalto University \\ Finland
}

\author{
Turkka Keinonen \\ turkka.keinonen@aalto.fi \\ Aalto University \\ Finland
}

\begin{abstract}
Smart technology turns the home into an active agent, which shifts the power structure within the household. This paper examines how initiators of smart technology insert their vision of the good life into households, and how these technologies exert power over the residents. Through a thematic analysis of interviews with five households, we consider Foucault's theory on disciplinary power to examine how smart home technologies shape the experience of the home by shifting the flow of information and thereby reify power structures. Results indicate that the implementation of smart technology can affect access to shared spaces, constrain interactions, and predefine practices thereby establishing hierarchies within the household. We turn the discussion towards ethical challenges concerning control, whose problems the smart home is concerned with, and how the smart home embeds itself in the household. We conclude with design considerations and future work.
\end{abstract}

\section{CCS CONCEPTS}

\section{- Human-centered computing;}

\section{KEYWORDS}

smart home; ethics; relationships; discipline; control mechanisms

\section{ACM Reference Format:}

Nils Ehrenberg and Turkka Keinonen. 2021. The Technology Is Enemy for Me at the Moment: How Smart Home Technologies Assert Control Beyond Intent. In CHI Conference on Human Factors in Computing Systems (CHI '21), May 8-13, 2021, Yokohama, Japan. ACM, New York, NY, USA, 11 pages. https://doi.org/10.1145/3411764.3445058

\section{INTRODUCTION}

As smart technologies reshape and realign power structures and relations [43], the role of the design of these technologies comes into question. Design has the power to both destroy and rework practices, placing responsibility on designers to consider what practices they support or dismantle [49]. It has been argued that technology should support control over family life rather than control over devices, extending our relation to technology beyond devices and towards a socio-technical narrative of shared environments and activities [6]. Digital technologies allow seemingly conventional

Permission to make digital or hard copies of part or all of this work for personal or classroom use is granted without fee provided that copies are not made or distributed for profit or commercial advantage and that copies bear this notice and the full citation on the first page. Copyrights for third-party components of this work must be honored

For all other uses, contact the owner/author(s).

CHI '21, May 8-13, 2021, Yokohama, Japan

(c) 2021 Copyright held by the owner/author(s).

ACM ISBN 978-1-4503-8096-6/21/05.

https://doi.org/10.1145/3411764.3445058 technology that has been updated with connectivity appear to abide by the same rules as traditional versions but are in reality entirely different technologies [37]. With these challenges in mind, this research sets out to discuss how smart home technologies for purposes such as lighting, heating, or security, have implications for the distribution of power and labour within the home. Our analysis explores a socio-technical narrative of control - inspired by Foucauldian theory on disciplinary technologies [15].

The smart home has been an on and off buzzword for the past 30 years, despite technologies only becoming commonplace in the last few years. The term smart technology generally refers to technology with some level of automation, sometimes referred to as intelligence or smartness, which is usually accomplished through digital technologies. In line with Harper's [22] argument that smartness builds on interactive technologies, the homes in the study presented in this article all have multiple connected systems that allow the residents to interact with their home through digital devices. Much of the discourse on the ethics of smart technologies revolves around privacy and data security, and security has been pointed out as the main ethical challenge for smart home technologies [28]. Although feminist researchers have addressed the smart home as a tool of control in situations of domestic abuse, showing how smart home technologies are used to harass, intimidate, and stalk [3, 16, 25, 29], there is still a gap in how they may affect power relations over time in an everyday setting.

This research takes place in households with couples in heterosexual relationships in Nordic countries and explores how smart technology is embedded in their households. Prior research has shown how technical identity and gender are co-constructed by the users and that digital housekeeping work is also identity work $[38,39]$, indicating that there are also underlying issues tied to gender performativity in the data. The homes in this study are in private ownership, and the inhabitants have lived in them for at least a few years, rather than for example co-housing, or public housing contexts. The study explores how technology embeds itself into social relations rather than how it affects or is affected by family psychology. This paper is concerned with how household members express their experiences about living with smart home technologies when interviewed and how the technologies reshape or reify existing power structures within the home. We consider how various mechanisms in smart technology act as intermediaries that shift power relations towards one member of the household.

\section{RELATED WORK}

\subsection{Perceptions of the Smart Home}

The smart home can be seen as an aspect of building a world where data and technology mediate all human practices [43]. The smart 
home shapes the way we experience the home and by extension it shapes society at large. Ethical discourse of the smart home has often focused on extreme cases such as security breaches, privacy violations, and domestic abuse but smart technologies also have more subtle effects on what we consider as the home, how domestic labour is conducted, and how we interact in the home. Common uses of smart home technologies are often derived from healthcare or technology for ageing where some loss of agency or privacy can be considered an acceptable trade-off in order to maintain as much normalcy as possible, but a similar trade-off is more questionable in a home where the residents are healthy and able.

The implementation of smart home technologies can be described as an attempt to perform a specific vision of 'the good life', one which is usually realised by a technologically interested male who manages the resources of the home [43]. This archetypal male technologist is often characterised by their interest in energy and efficiency and the elimination of most household labour, and their skills to pursue these through economics, engineering and computer science [43]. In this vision the smart home promises comfort, safety, and cost or energy-saving through automated domestic labour. The ability of the smart home to deliver on the above promises can be questioned. The modernisation of households through technology has at times generated more domestic work overall [4]. Regardless of the validity of the vision, the implementation of the smart home changes the structure of the home. By exploring the lines of inquiry in research on smart homes Wilson et al. [52] identify privacy and control as primary concerns. By examining the users, they also identified three narratives of control in the smart home: functional, instrumental, and socio-technical. The functional narrative of control explores what can be controlled, while the instrumental narrative treats control as a means to an end The third, socio-technical narrative is similar to Strenger's notion of how smart technology can re-negotiate relationships between different social and technological agents [43].

The idea of the home is easily taken for granted but it proves difficult to establish one specific definition. The home can be considered, among other things, a place of security and control, a reflection of one's ideas and values, a material structure, an indicator of personal status, and a centre of activities and relationships with friends and family [10]. Mallett [27] also argues that the home can be simultaneously understood as a physical dwelling, a lived space of interaction, a space of comfort and security as well as oppression, or a symbol of status depending on the domain of study. Gram-Hanssen and Darby [18], building on the previous work of both Després and Mallett, identify four aspects of the home in order to study the relationship between smart technology and the concept of homes. These aspects are the home as a place of 'security and control', 'activities', 'relationships and continuity', and 'identity and values'. The homes explored in this study are owner-occupied, and explored as a shared site of relationships, control, and as the introduction of technology affects the internal relations of the home, also as a site of conflict.

\subsection{The Smart Home as a Construct}

A smart home can be constructed in several ways: with technology integration, technologies that offer smart services, or interactions with smart technologies. The physical home can both be built explicitly as a smart building, or smart technology can be integrated into an existing home. The smart home can also be considered to consist of technologies that continuously collect data and act upon it, whether controlling heating or security systems [18]. However, these systems do not act independently but rather based on interactions with the inhabitants who program and maintain them. Many smart homes are built by the people who inhabit them and are therefore set up and programmed by residents. New technologies are also designed to learn from the inhabitants, such as smart thermostats which aim to learn from user behaviours to better predict needs [53]. Whether the devices are set up and left to run by someone initiating the technology, reprogrammed over time to better fit needs, or learning from the behaviours of the inhabitants, the smart home is created through interactions with the inhabitants.

The application of smart home technologies covers a range of functions, but common examples are security systems, power saving or utility systems, systems of convenience aiming to free up more leisure time, and entertainment systems [21]. Strengers et al. [44] place these technologies in three categories derived from Intel's vision of Ambient Computing: protection, productivity, and pleasure. Although these are installed for mixed reasons, they commonly aim to optimise a function through the use of some kind of connected or automated system. The optimisation is done by monitoring and controlling aspects of the house [18]. Gram-Hanssen and Darby [18] extend the home beyond the walls and adopt a definition of the smart home as homes which contain a "complex communications network, allow for remote monitoring and control, and provide services to both occupants and electricity system operators", arguing that the smart home has been devised by energy researchers to assist with system management inside and outside the physical home.

While the market for smart homes has expanded and the technology industry is pushing for more smart homes, Darby [5] expresses that there is "dearth of evidence" to support any reduction of energy use in smart homes. Jensen et al. [24] explore how desire shapes energy consumption and how desires embedded into smart home technologies both complement and conflict with each other. There is also research suggesting that smart technologies enable energy intensive lifestyles and practices [47] similar to how the industrialisation of the household created new practices [4]. Rode and her colleagues [38-40] have explored how men and women use programming and technology as a way to construct their gender identity in a domestic context. While smart technologies enable new practices of digital housekeeping, Strengers and Nicholls observe that practices relating to researching, updating, and maintaining these technologies are often performed by men [45]. Aligning with Strengers' [43] archetype of technologically interested and savvy men, the smart home is usually initiated by the male partner in the household is well documented in existing research [17, 32, 46]. The initiators are, for reasons such as interest in technology or economical savings, the ones installing or advocating for the use of technology.

Through the various technologies that are integrated in the smart home, it is not constrained by the physical building but also extends and connects beyond the walls of the house $[6,18]$, whether by detecting the location of the residents or by active control from 
outside the home. The smart home is therefore defined by the physical building, the technologies that connect and monitor the activities both in and beyond the building, and the residents whom it can engage both directly and indirectly with.

\subsection{Privacy and Ethics in the Smart Home}

In prior research, the desirability of the smart home is often questioned, focusing for example on the obstacles of adopting the smart home [2]. Some of the obstacles for adoption are factors such as privacy, reliability, technological complexity, interoperability, and cost. While reliability, complexity, and interoperability are perceived as technological concerns, privacy is often forward as the primary ethical challenge for smart home technology [48, 54]. However, there are ethical considerations in the home that go beyond privacy and security, as they are only a part of the many issues that affect social change within the home [12]. Pierce questions smart home security by developing concepts for how to explore potential benefits and dangers of smart home technologies through social acceptability and how design may act to normalise previously unacceptable technologies beyond the so called 'creepy line' [35]. Smart home devices can reinforce existing power imbalances and the introduction of smart home technology tends to both reinforce existing power structures and concentrate control to one person [20]. Geeng and Roesner [17] show how smart home devices affect intra-household privacy and can play a role in causing tension between users, especially when faced with inequal levels of control over the technology. As noted above, the smart home is often initiated, installed, and managed by the male partner in the household, giving them greater control over the devices in the home [17,32]. The active initiators have been compared to drivers whilst other household members take the role of passive users [9]. However, some research suggests that the drivers are motivated by their interest in technology rather than its practical benefits while the passive user, who is often the driver's significant other, has been described as quietly disinterested but supportive if they find a function useful [9]. This has led to debates on the need to consider non-expert users in order to address how these technologies affect power balances within the home $[17,32]$ as well as a need to better understand of the co-construction of gender and technological identity [39].

Parallel to the privacy concerns of the smart home is the related discussion of persuasive technologies. Persuasive technologies refer to different ways of causing behaviour change by triggering various cues [14]. The aim of persuasive technologies is often to reduce errors or encourage positive behaviours [26], but it can also be paternalistic or enforce behaviour that is not desirable for the user. Persuasive technologies are not coercive but rather reinforce positive behaviour through encouragement or modelling a target behaviour [14]. While avoiding errors is a desirable outcome, the use of persuasive technologies raises ethical questions on whether it is acceptable to deliberately influence behaviour in specific directions or if it can cause 'moral laziness' by delegating ethical decisions to machines [51]. In order to avoid technologies interfering with the agency of human actors one response has been to make the processes of smart technologies more transparent [50]. However, as Nagenborg [33] argues, persuasive technologies may become unethical even when self-imposed when used to encourage compliance. But as technology always mediates our perception and interaction with the world, human agency instead explicates the responsibility of designers to attempt to anticipate, assess and if needed redesign the technology to achieve desirable results [51].

\subsection{Operating the Smart Home}

The practical operating of the smart home relates to the functional and instrumental narratives identified by Wilson et al [52]. The functional narrative revolves around achieving enhanced functionality and technological control over the smart home, while the instrumental narrative examines the interactions with these technologies and how to design for the user experience. The functional is intimately interconnected with the instrumental narrative of how to interact with these devices. The smart home systems can also be separated into two modes: monitoring sensors and devices that respond, i.e. actuators. The sensors can remain relatively invisible but are crucial in automating the home. Setting up smart technologies involves making explicit rules. They commonly take the form of IF statements, such as If This Then That (IFTTT). If doors are unlocked, send a notification. If the air quality falls below a threshold, turn on ventilation. However, only some smart technologies are automated while others are simply connected.

At the moment mobile phones are the primary mode of interaction with smart home systems. This type of interaction is based on a model of single or individual users, while the home is a social environment with families or housemates sharing a residence, requiring them to find ways of sharing the environment and resolving any conflicts that arise. Designing technology for shared spaces requires designers to be aware of how the design decisions will affect the users' actions and potential conflicts through understanding which actions are made easier or more difficult for the users [11]. According to Niemantsverdriet et al. [34] people avoid using multi-user home technology that risks causing a conflict as a way to avoid conflict itself. Intelligent reactive systems are used to predict user preferences in order to avoid conflicts [34]. However, as demonstrated by Geeng and Roesner [17], setting up a smart system is not done by the household as a whole but by interested parties who may reify their ideal use of a space or interaction through technology, making the conflict invisible or shifting the conflict from an interpersonal conflict to one between the residents and the system.

Although mobile phones are a common tool used to interact with the smart home, there are also others, such as voice assistants and web interfaces that can be accessed from any device, as well as physical presence and interaction as an interface. Personal mobile devices are ostensibly pervasive and offer significant computing power, and although multiple mobile phones can be connected to a system, each device is designed for single-user interactions [34]. In the past years, smart speakers have also become a common feature in smart home technology, especially to control audio or lights. Porcheron et al. [36] have explored the way in which Voice User Interfaces (VUI) function in situated collective actions within the home, suggesting that designers should focus on basic functionality over embedding them in conversational interactions. Web interfaces are often used to either program the home or to check on devices that do not require immediate interaction, such as heating 
or ventilation. There are also implicit interfaces. Implicit interfaces use the interactions themselves as an interface, moving the technology into a supportive role that does not require direct interaction. Implicit interfaces often use predictive technologies which collect data and analyse patterns in order to anticipate user needs. Predictive technologies are a part of what Aldrich [1] considers to be a smart home, using technology to anticipate and respond to the needs of the inhabitants in regards to comfort, convenience, security, and entertainment. Serim and Jacucci suggest that researchers and designers should consider how implicit interactions relate to the mental models and intentions of the users [41].

\section{CONCEPTUALISING CONTROL}

\subsection{The Home as a Site of Control}

The work of Foucault has been discussed in the context of smart technology, for instance in the context of governance [7] or surveillance $[19,30,31,42]$, showing how a Foucauldian analysis can be used to understand surveillance technologies. Foucauldian analysis of power relations has also been used in the context of design, where it can either further or resist existing power relations but this requires awareness of the implicit power relations and their dynamics [23]. Whilst discussing governance De Laat [7] argues that, though focused on the body, theories of Foucauldian discipline can be useful to understand how Machine Learning creates discipline. De Laat [7] also identifies predictive discipline, which focuses on the mind, as a prominent disciplinary tool in algorithmic processes. Deleuze refers to family, alongside governmental institutions, as an environment of enclosure in his "Postscript on the Societies of Control" [8]. Deleuze argues that the control society replaces the disciplinary society, and that in control perpetual training replaces the examination of discipline [8]. The shift from discipline to control does not mean that the disciplinary methods are gone, but that they have shifted their purpose so that the enclosures are continuous and ever-changing, while disciplinary institutions have a more stable form [8].

The Foucauldian analysis of disciplinary power examines institutional systems as a tool of domination by investigating how governmental institutions over the past two centuries have become simultaneously more enlightened and more precise in how they exercise power. Foucault challenges the notion that schools or judicial systems serve to empower citizens claiming that these institutions have instead become increasingly efficient tools of control. The three primary techniques at the core of Foucault's vision of discipline: hierarchical observation, normalising judgement, and examination [15], can all be seen when exploring smart domestic technologies. Foucault argues that hierarchical observation is a prerequisite for discipline, serving for more accurate judgements. As the subjects are observed, it is also vital for normalised judgements; that is establishing a standard for individuals to measure themselves. The examination combines observations and normalised judgements in order to qualify, classify, and punish. In the smart home, there are sensors across the home to observe both environmental changes and the movements of the inhabitants. These sensors also provide a plethora of measurements through which the behaviour of the inhabitants can be judged. At any time, the smart technology also allows to examine the data of the inhabitants to judge how they are behaving. Although the home is a very different site from those which Foucault observes, as noted above it is a space with many different functions that in various ways respond to the disciplinary powers that Foucault discusses. The argument made here is not to claim that homes are institutions in the same sense as governmental institutions but rather that the tools of discipline are mimicked in the smart technologies of the home.

Through automation the smart home gains a form of disciplinary power when the inhabitants fail to follow the assigned procedures. As Foucault notes, disciplinary power serves to train rather than select [15]. In the smart home, the systems train the inhabitants to be more efficient, in this case efficient means obeying the rules of the house more readily. In order to train the inhabitants, the smart home must observe the events in the house through the sensors installed.

\subsection{Exploring Narratives of Control}

By recognising the home as a site of control and the smart home as an construct consisting of humans, the physical space, and technology this paper extends the ethical discourse of the smart home beyond surveillance, data, and security, and adds to that of control previously explored by feminist researchers [16, 25, 29]. As noted by Strengers [43] the politics of the smart home is an attempt at performing a specific vision of the good life, while Wilson et al. [52] recognise several narratives of control that in different ways aim to create or explore this. These technologies provide greater control to the initiators while affording a different experience to other members of the household. Our research considers how technology functions as an intermediary in social relations and how disciplinary mechanisms are integrated into designs which generate or reinforce hierarchies within the home.

\section{STUDY DESIGN}

\subsection{Interview Study}

Two series of semi-structured interviews [13] were done with five households (See Table 1) where the residents have installed multiple smart systems of various kinds. The interview studies focus on technologists (henceforth referred to as initiators) as prior research shows that smart home technology is usually initiated by one person $[17,43,46]$. In the first series, the households were found by snowballing for technologists. In the second series of interviews, the partners of the initiators were invited to give their perspective on the smart homes they live in. As two of the partners declined to participate, there was a total of 8 participants in the study. The initiators who lead the installation of the smart home in this study are male. This is in line with traditional patterns of how technological identities and domestic labour are assumed to be divided $[17,39,43,46]$

Each interview with an initiator took between 1-2 hours. While the partner interviews were generally shorter and took 20-60 minutes, similar amounts of time were made available for both interviews. The initiators are skilled professionals, some working as entrepreneurs or researchers, and in some cases with decades of experience having begun the process of exploring smart homes more than 20 years ago. The initiators are reminiscent of Strengers's [43] archetype of men who are technologically interested, educated, and 
Table 1: The participating households and the stated drivers behind building smart homes

\begin{tabular}{|c|c|c|c|}
\hline ID & Household & Description & Stated Drivers \\
\hline 1 & $\begin{array}{l}\text { Heterosexual couple with two } \\
\text { children who have moved out. }\end{array}$ & $\begin{array}{l}\text { Built as a smart house. Extensive use of smart technolo- } \\
\text { gies with programmable lighting throughout the house, } \\
\text { heating systems connected to both the hot water and } \\
\text { the fireplace, as well as entertainment systems. }\end{array}$ & $\begin{array}{l}\text { A mix of interest in smart home } \\
\text { technologies and reducing en- } \\
\text { ergy costs. }\end{array}$ \\
\hline 2 & $\begin{array}{l}\text { Heterosexual couple with two } \\
\text { children, one still living with } \\
\text { them. }\end{array}$ & $\begin{array}{l}\text { Old house that has had smart technology integrated. } \\
\text { The smart technologies are focused on utility, with tech- } \\
\text { nologies measuring air quality, humidity, and heating. }\end{array}$ & $\begin{array}{l}\text { A desire for easing maintenance } \\
\text { of the house and reducing costs. }\end{array}$ \\
\hline 3 & $\begin{array}{l}\text { Heterosexual couple with two } \\
\text { small children. }\end{array}$ & $\begin{array}{l}\text { All of the technologies are commercially available. } \\
\text { There is smart lighting throughout the home, smart } \\
\text { speakers, kitchen appliances, smart doorbell. }\end{array}$ & $\begin{array}{l}\text { Interest in technology and a } \\
\text { desire for conveniences in the } \\
\text { home. }\end{array}$ \\
\hline 4 & $\begin{array}{l}\text { Heterosexual couple, children } \\
\text { have moved out but grew up with } \\
\text { smart technology. }\end{array}$ & $\begin{array}{l}\text { Built as a smart house in the late 90's. Technologies } \\
\text { involve material choices, heating, air quality, and con- } \\
\text { nectivity. It was highly advanced when built, among } \\
\text { other things it involved pre-commercial development } \\
\text { of internet-connected doorbells. }\end{array}$ & $\begin{array}{l}\text { A desire to explore the possibili- } \\
\text { ties of smart home technologies } \\
\text { and how they can improve the } \\
\text { quality of life. }\end{array}$ \\
\hline 5 & $\begin{array}{l}\text { Heterosexual couple with two } \\
\text { children who have moved out but } \\
\text { grew up with smart technology. }\end{array}$ & $\begin{array}{l}\text { Built in the early } 2000 \text { 's and utilises wired smart tech- } \\
\text { nology throughout the house to control lights, heating, } \\
\text { security, as well as entertainment system. }\end{array}$ & $\begin{array}{l}\text { Interest in technology and a de- } \\
\text { sire for conveniences that re- } \\
\text { duce domestic labour. }\end{array}$ \\
\hline
\end{tabular}

in charge of managing resources (technology and energy) in the home. All of the participants were from the Nordic region. The smart homes belonging to the participants were built or converted to smart homes between 1998 and 2017, and the residents have either lived there together since the house was built (Household 1, 4, and 5) or since before the implementation of the smart technologies began (Household 2 and 3). All of the initiators are also involved in developing and designing new technologies for their home aside from the initiator in Household 3 whom expressed a desire to do so in the future. Three houses (Household 1, 4, and 5) were built with smart technologies incorporated from the beginning, while two of the Households (Household 2 and 3) have integrated smart technologies into in existing houses. The houses have all been subject to ongoing upgrades or development since, spanning a significant period of technological development. All of the houses in the study were freestanding villas owned by the residents. The participants were not paid. They were interviewed alone in order for them to not be influenced by their partner's statements. The partners in Household 4 and 5 did not wish to participate in the study, nor did they offer any reason for why.

\subsection{Analysis}

The transcribed interviews were coded through thematic coding, where the first coding was set up by two researchers, one author and one external researcher. The codes were first generated while analysing the initiator interviews and then used for the partner interviews. When analysing the partner interviews, the same codes were used in order to analyse how they experienced the same technology. The data was analysed to explore how power is exercised in the smart home and towards whom. The coding was done to explore how technology is socially embedded and experienced, both by the initiators and their partners. The participants were asked to describe the technologies in their homes, as well as what they liked, disliked, or found frustrating about the technologies. During the interviews the initiators were asked about their motivations for installing or building the technologies, and what they considered to be a smart home. After the first coding, there were nine codes used to explore mechanisms of control. The ones that were finally used were 'direct management' and 'house management', while others related to definitions of the smart home, motivation for having a smart home, UX problems, managing, or perceptions of their partner. Direct and house management refers to implementations of technology aiming to either manage the environment of the house or to encourage certain behaviours. By analysing the codes of 'direct management' and 'house management' we identified five themes or mechanisms whereby the smart home exerts power and regulates the activities of some of the residents. In these five themes the initiator has attempted to employ some form of control over the house which has then extended itself on other members of the household, creating different experiences of the same technology.

\section{RESULTS}

In the interviews, the participants would describe the technology in their homes, both their favourite technologies as well as their least favourite ones. In this chapter we present five types of technologies which one or more of the homes contain. They were selected based on how they in various ways exemplify attempts to deploy and manage technology in the house that in turn changes the structure of the social relationships of the household. All the technologies aim to, in different ways, gain control over the environment but at the same time they often also exercise control over the inhabitants. The way the initiators experience the technologies is often different compared to their partners. Each description of the type is primarily described from the perspective of a particular household, in order to give a richer description of how that technology affects the social 
Table 2: Summary of themes and example technologies

\begin{tabular}{lll}
\hline Theme & Example of Technology & Description \\
\hline Overt Observation & Smart Doorbells & Explicit monitoring of interactions with the home. \\
\hline Discreet Observation & CO2 Meters & Implicit monitoring beyond the primary aim of the technology. \\
\hline Constraining Interactions & Voice User Interfaces & Defining how to interact with the home. \\
\hline Regulating Commodities & Showers / Hot water & Defining how and when commodities can be accessed. \\
\hline Predefining Practices & Lighting & Defining what practices a space is suitable for through technology. \\
\hline
\end{tabular}

structure of the household, however the technologies themselves are often available in some form in more than one of the household.

\subsection{Overt Observation}

Overt Observation is done through devices which explicitly monitor the actions of residents. Internet-connected doorbells are present in households 3, 4, and 5. The initiators express strong satisfaction with the smart doorbells. They allow inhabitants to answer the door or receive packages when they are not at home. In this way, inhabitants can control the home through overt observation, without being physically present. One initiator suggested that if someone expresses an interest in the smart home, a smart doorbell is the best starter device. The smart doorbell will offer an event history with a video and audio feed of what has happened outside the door. Similarly, another initiator also expresses satisfaction with an older version of the smart doorbell as it allowed him to open the door when someone forgot their keys. Disagreeing with the initiators, the partners in two of the houses express no interest in access to the smart doorbell themselves, one of them stating that she dislikes it as she feels that her husband is always watching her, "Whenever I walk in, whenever I open the door or close the door I'm being watched. Like this morning and I go out with some trash and [Husband] asks, what did you do, because he got a notification and it's like, let me go out the door without being asked, you know [laughs]. I just went out with some trash.” The smart doorbell removes the need to communicate or ask in order to be aware of events, instead informing the initiator through the app, in return for the convenience of being able to answer the door. The smart doorbell offers the owner direct rather than automated control. However, because it is under direct control, it allows the owner to overtly observe and control the environment, which also causes one partner to feel surveilled.

\subsection{Discreet Observation}

While Discreet Observations are reminiscent of the Overt Observations, they are differentiated in that the observation of other residents is not the primary aim, these observations appear unobtrusive and are aimed at improving or maintaining the systems within the house. Air quality is considered one of the important aspects to improving the health of inhabitants. Both Household 2 and 4 have automated controls for ventilation, which is also an important cost factor for the households. The technology also allows for discreet observation of both the house and the household. While travelling, the initiator of the Household 2 noted that the $\mathrm{CO} 2$ levels in the master bedroom were higher than they should be, and realised that his child must have moved into the master bedroom while the parents were travelling. This was also a funny story for the partner, she explained that you never know what teenagers might be doing while you are away. The partner also feels that the technology is a source of comfort when they are travelling as her husband is always able to check on the house. It also shows the change in the flow of information, as the initiator is able to check what is happening in the home without interacting or informing anyone. Rather than the overt observation above, the monitoring can be done discreetly while bypassing any interactions with the other residents, discreetly observing not only the status of the house but that of the other residents.

\subsection{Constraining Interactions}

Some technologies require the users to adopt particular models of use. Voice User Interfaces (VUI) such as smart speakers are encroaching on smartphones as a way of interacting with the smart home. One of the participants considered VUI's the most convenient way to interact with their smart home, stating: "I think that will be one of the key elements in the future how I control everything", while other participants see it as needless technology largely intended for showing off. However, VUI's also constrain the interactions in the house by supporting a particular model of use. When discussing the technologies of the household, the partner in Household 3 stated that she usually manages to adapt, but that a change of smart speaker technology caused her to lose her playlists. She further expresses that she finds some of the speakers frustrating because they sometimes do not respond to her, but only to her husband. She expresses that because she doesn't really know how they work she copies the way her husband uses them. When they do not work, she admits that she is able to access the devices through her mobile phone, but finds this frustrating as she feels that she "would like to be free of the phone". Similarly, in the work of Porcheron et al [36], one partner perceives that the VUI understands her husband better by stating "it does it for you". What is a convenient new technology to her partner fails to offer her the same satisfaction. While the VUI appear convenient, they also require the partner to adopt the initiator's preferred model of use. The partner is no longer free to put away the phone if they want to be able to command the home, as the vision of use in the smart home implies having the phone available.

\subsection{Regulating Commodities}

Technology is used to regulate what has previously been easily accessible commodities. Hot water is a commodity immediately within reach in most homes, however in an effort to save energy 
Household 1 has a system that prevents showers at any given time, but instead requires the inhabitants to notify the system in order to have a warm shower outside of normal hours thereby regulating available commodities. For the initiator, having to take a cold shower if he's failed to notify the system is simply his own fault saying: "Oh gosh I've forgotten to switch on the heating and now I need to take cold shower. And then I would say that well... that's my bad and I will do that." However, the partner is frustrated with having to ask her partner whether there is hot water for a shower or if she needs to wait, expressing: "But if I want to go shower we don't have warm water. So, I can't live in my house like I would like to live." The initiator has set up the way that the warm water works in the house which while saving energy, appears not to be established within the household nor reflective of how heating works in the surrounding community. The initiator has continuously worked to optimise the heating. While optimising the house by gradually working on the algorithms that define how to heat the water, he also says that optimising the smart home is both the technology and the behaviour of the inhabitants: "It is actually both [the house and the humans]. It is very much both." There is equal access to hot water but the rules are written by the initiator, regulating the available resources for showering.

\subsection{Predefining Practices}

A technology can be used to define the ways in which a space may be used. The automation of lights is a common technology that several participants have experimented with, often noting bathroom lights that turn on automatically and lights with a timer among their better home technologies. They can be turned on or off automatically or on command, offering the possibility of using lights to make the home appear inhabited whilst on vacation. The way lights are set up can also predefine what practices a space is used for in the home or how it is used. In Household 1 the initiator notes that he was also able to turn on the lights for his partner while she was working from home, although he notes that it is a problem that she wasn't sure how to do it herself. From the partner's perspective, she expresses that she would prefer to use traditional switches and that when her partner is away she minimises her interactions with the lights, saying that: "I minimise everything. The lights. I often use those old lamps." She also expresses frustration with how they are programmed to turn on in order expressing that "It's like a disco. So maybe you understand that it's not so nice. At the moment it's good because it's summer almost, or anyway there's the light is coming outside so we don't need that". She prefers the summer because it lets her interact less with the lighting in her home. While the initiator enjoys the advantages of the technology, the partner expresses that "It's like enemy. The technology is enemy for me at the moment." While the partner is limiting the influence of the smart home, the initiator is willing to extend their personal sphere of influence beyond the home. In Household 1 the initiator has extended the home to respond to when his phone connects to nearby cell towers, allowing it to respond to him coming home or leaving by turning on and off the lights in the yard. In Household 5 the initiator expresses that it is a good feeling when the house recognises you as you come home: "It's sort of like dogs when you come home, that the dogs come and meet you. It feels nice." Automating the lights offers the initiator the ability to set the house according to their preferences. Instead of turning lights on and off according to the preferences of the people in the room, the possibility to negotiate this is taken over by the smart home system where a change requires asking the initiator to adjust the settings.

On their own many of the technologies described above may appear as inconveniences, rather than an attempt at taking control over the home. However, through monitoring and controlling what kind of behaviour is acceptable or supported, constraining interactions according to one person's concept of use, or when to use different utilities and commodities it becomes a system of tools that train the residents to live according to the ideals of the initiator, whether intentionally or not.

\section{DISCUSSION}

Smart technology reshapes the power balance of the home by introducing new tools to control our environment and handing control to the home itself. In the process of extending control over the home, smart technologies change the way that power is constituted through overt and discreet observation, constraining interactions, and by predefining practices in the home, thereby re-aligning the network of relations within the home. The stated intents or drivers are derived from interest in technology, a desire to optimise costs, and conveniences or ease of living, all of which involve control over the space, but that control over the space is difficult to untangle from the control over other residents. By living inside the smart home, the residents accept the authority of the technology and the stated intent of the initiators concerning cost and convenience. The technology itself is concerned with training and disciplining the residents to obey the rules, thus extending control over our lived environment, in service of the initiator but not necessarily with the same aim. The mechanisms outlined in the interview study show how the technology becomes embedded in the interactions, reinforcing power structures by shifting the flow of information.

Resolving privacy and security issues may address some of the concerns raised about the smart home [2, 48, 52, 54]. However, even self-imposed surveillance technologies may incorporate persuasive elements that can create ethical issues surrounding the autonomy of the actors [33] and Geeng and Roesner [17] show, we should consider how the smart home affects intra-household relations by reducing privacy between the residents such as in the case of 'Discreet Observations' where the privacy of others can be violated simply through checking the air quality. While transparency enhancing technologies could make the persuasive elements clearer [50] they would not take into account the difference in interest in the technologies of the smart home, where only the initiators take an interest in the data. Pierce's concepts around social acceptability [35] could prove useful for considering these implications and ought to be taken a step further to consider intra-household relations. While Pierce considers how 'digital leakage' occurs between neighbours, our analysis suggests that similar concerns are important within the household as we see in both 'Overt Observation' and 'Discreet Observation'. Although Verbeek [51] argues that the question of human autonomy in persuasive 
technologies is somewhat debatable as all technologies can be considered persuasive to some degree, thereby placing responsibility on the designer to anticipate and assess the technology, he also notes that they can establish normative ideas where the designer externalises their moral values. The above examples of 'Regulating Commodities' and 'Predefining Practices' show how one vision of use can be handed over to the house, thereby externalising the values into the house. They also show how inserting one technology in the home can impact other interactions in unintended ways, making the residents use the home differently as the smart technology affects the entire home, not just the interactions with the technology directly affected. While the mechanisms we explicate show how the intra-household relations are affected, the same mechanisms could be re-interpreted and would gain a different meaning if we analyse the relationship between companies and households. If the mechanisms we identify were to be interpreted through Pierce's [35] concepts of 'hole-and-corner applications' which obscure the use of technologies that are not beneficial to the user and 'foot-in-the-door devices' which serve to normalise new technologies and corporate agendas they would take on a different meaning due to the changed social context.

6.0.1 Convenience and Self-Improvement. Interactions with technology can be designed to prevent transgressions against rules entirely. However as outlined here, if transgressions are done against the system rather than other residents, the extent of control mechanisms range from relatively minor inconveniences or shifts in information to direct discouragement. This was the case with regulating commodities: actions were never explicitly forbidden but a trade of convenience or cost was offered in return for obedience. Following Verbeek's [51] argument on how the existence of a technology transforms our actions, the existence of these technologies makes not utilising them an ethical choice as the possibility of taking action exists. To not install CO2 measurements in the bedroom while struggling with bad air quality or neglecting to install a 'smart' security system despite fearing a burglary, can raise the question of whether one has done enough to prevent possible negative outcomes, and if you are concerned with the environment why wouldn't you give up some agency in order to reduce environmental impact?

Smart technologies discipline users under the guise of selfimprovement. According to Strengers [43] these technologies are an attempt to perform a particular vision of the good life, but in doing so they also sidestep other desirable ways of living by avoiding household communication in that particular situation. Rather than being responsible to your fellow residents when you forget to open or close a window (or prefer to keep it open), you become responsible to the smart home which observes your actions. You no longer need to discuss who forgot to lock the door, the system can tell us that and it functions to 'improve' your behaviour to better follow the rules picked out.

6.0.2 Power is Not Unidirectional. However technology is not unidirectional from the initiator towards other household members, it also acts back towards the initiator. In all the cases discussed here, one party has been the initiator of the system. This also matches previous research $[17,32]$. The technology is introduced based on the preferences of the initiator, even in Household 3 which largely consists of commercially available systems, the technology has been introduced by one party. While the initiator has gained power over the environment, and by extension over other inhabitants of the home, the power also disciplines the initiator. The initiator is required to serve the smart home systems, to maintain them in order to maintain control over the environment. One participant comments that it is "tedious to keep everything working all the time." Maintenance becomes a time-consuming practice where nonfunctional systems can cause frustration among other inhabitants. The smart technology of the households are also ongoing projects where changes are made continuously, and while major changes or new technology might be subject to shared approval, small changes are part of maintaining the home technologies.

The smart home tends to concentrate power towards those who already have power [20]. As existing, often gendered, power structures are amplified, this also means that the way the smart home disciplines the residents is experienced differently by the initiator than by other residents. This is in part because the controller understands not only how the rules work, but why they function the way they do. They may be aware of technological limitations or have written rules to support the way they believe that the home should function. However, once power is no longer exercised in interactions between residents but by the house itself, it is no longer a conflict of interest between the residents, but between a resident and the home. In this way, technology serves to further shift the power balance, as technology can 'prove' wrongdoing, but only for the people who control it. Knowledge and understanding gives the initiator a different perspective when something goes wrong. It is not simply the house failing to comply; they might understand why it fails to comply. In the example of Regulating Commodities, the initiator has written the rules he is subjected to while his partner is merely subject to them. These different roles for the members of the household reveal another layer of Foucauldian disciplinary control: hierarchical observation and judgement creates a form of discriminatory power [15], separating supposedly equal members of the household through the various mechanisms of control. Despite everyone technically having the same amount of access, the controlled limitation requires the other residents to conform to the initiator's vision for how to conduct daily practices. While each of these technologies is not a significant infringement, the smart home, through its range of mechanisms of control, can shift the power balance in the home.

6.0.3 The Smart Home Divides. The exercise of power can make conflicting views visible, where one party feels surveilled or powerless. With more obvious mechanisms there is a clear path of resistance towards the initiator. However, if the home is perceived as the one exercising power rather than the other residents, anger may be turned to an impersonal entity that cannot be argued with, fought or even resisted. In this way the smart home is not passive, it is actively exerting power over the residents. Although recent work has been done to both consider the gender imbalance of the smart home, how smart technologies can be potentially abusive as well as recognise the digital housework that the technologies enable [44], there is still insufficient understanding of how the smart home technologies train the residents, both the initiators and the other members of the household, into different roles. Practices and 
social roles can be built into the technology and without recognising the active role of design, the exercise of power fades into the background.

\subsection{Design Implications}

By recognising the mechanisms by which the smart home exercises power, this paper has explored how the smart home exerts power and how this affects household inequality. In several of the examples the lack of access is related to lack of interest in technology or lack of understanding of the technologies, rather than the initiator deliberately denying access. The partners' lack of engagement is consistent with how digital identity is tied to gender performance $[38,39]$. While engaging non-experts or 'passive' users in the design process and decision-making is important to disrupt the patterns of control, further steps should be taken to understand how devices fit into a complex social system by considering The Smart Home as an Ecosystem. Focusing on addressing the Issues of the Household, rather than the perceived challenges of the initiator. We also believe it is important to consider the role of designers and who is a designer as Involvement Requires Equity.

The Smart Home as an Ecosystem To avoid creating further problems, we believe that designers should consider how the design affects other systems and relations that may not appear to be directly connected to the issue at hand. Some of these problems, such as in Overt Observation stem from both a lack of understanding as well as not recognising how solving what one resident perceives as a problem affects the other residents. In order to address issues of power designers need to recognise the existing ecosystem of the home and reflect on how new technologies may disrupt them.

Issues of the Household Solving problems that are perceived or understood by the initator may end up addressing individual problems, rather than household problems. In Constraining Interactions and Predefining Practices the initiator creates a solution that works according to their model of how to interact and use the home, without fully considering whether the solution improves the life of other residents. Design of smart home technologies should aim to resolve challenges concerning the home as a shared space. Technology may extend the capabilities of the users and should therefore address issues that improve the capabilities of the household as a whole.

Involvement Requires Equity Engaging the partners in the design is a part of easing some of the challenges of smart home technologies, however the role of the initiator is a core issue. In Overt Observation there is the possibility of equality of access, but the solution ends up favouring the initiator whom is already engaged and desires the technology. Technologies should be developed to allow for all members of the household to participate as well as to address existing inequalities. In the example Predefining Practices we can perceive the partner as being part of designing the home, she engages by resisting and adding to it through traditional technology. Designing the smart home is not merely designing the technology but also designing the entire space, design needs to recognise these practices as part of designing the smart home as well as provide ways of engaging with the technology that recognise and addresses inequality.

\section{CONCLUSION}

In this paper we explore how the smart home can affect the relationships of the inhabitants by extending one person's is over others thereby expanding the ethical discourse on the smart home beyond common concerns of privacy and security. By understanding the smart home as a site of control, we are able to understand that the focus on privacy does not address some important ethical concerns of the smart home. Some ethical concerns are addressed by recognising that the smart home as it currently exists is a highly gendered practice that appears to reinforce traditional gender roles as has already pointed out by Rode and Poole [39], yet this does not fully disclose how the smart home shifts the structure of the relationships. This paper contributes by explicating the disciplinary nature of the socio-technical narrative of control.

A further contribution of this paper is identifying some of the ways in which the smart home exerts power and limits the agency of some members of the household. We identify five mechanisms of control: Overt and Discreet Observation, which serve to remotely monitor and surveil the home, shift the flow of information and interactions. Constraining Interactions control how one can interact with the space. Regulating Commodities and Predefining Practices restrict use for unintended purposes. These mechanisms portray an overarching narrative of only extending the initiator's idea of the good life to other members of the household, but also to build it into the infrastructure of the home. While some of the aims of the smart home are clear, such as saving energy, the ways by which it does this are less clear. By recognising how the smart home is constructed by the building, the technologies, and the residents we are able to observe how it embeds itself into the social fabric of the household and affects the power structures within it. The various mechanisms are perceived to be disciplinary in nature and serve to train the residents to enact the good life, as it is perceived by the initiators. The disciplinary power of the smart home is exercised power both towards other members of the household, and back towards the initiators who become responsible for maintenance, thereby creating or reinforcing hierarchies and roles within the household.

In this paper we have explored what existing smart home technologies do and how they do it, rather than what they should do. For designers, whether they are building their own smart home or professionals designing these technologies this is a crucial challenge. The smart home should support the members of the household in living the lives they want, rather than reinforcing the initiators vision. We show how these technologies reinforce existing power structures, often tied to gender roles. There is no single way of addressing this challenge as there are multiple entanglements involved. However we argue that by treating the smart home as an ecosystem, focusing on household rather than individual problems, and reflecting on what design of the smart home implies and that through equity rather than equality of access it is possible to resist reinforcing existing power structures. Future work therefore requires prototyping new ways of embedding and interacting with the smart home that focuses on the smart home as a shared living space rather than a collection of devices. 


\section{REFERENCES}

[1] Frances K. Aldrich. 2003. Smart Homes: Past, Present and Future. In Inside the Smart Home, Richard Harper (Ed.). Springer London, London, 17-39. https: //doi.org/10.1007/1-85233-854-7_2

[2] Nazmiye Balta-Ozkan, Rosemary Davidson, Martha Bicket, and Lorraine Whit marsh. 2013. Social barriers to the adoption of smart homes. Energy Policy 63 (Dec. 2013), 363-374. https://doi.org/10.1016/j.enpol.2013.08.043

[3] Nellie Bowles. 2018. Thermostats, Locks and Lights: Digital Tools of Domestic Abuse. https://www.nytimes.com/2018/06/23/technology/smart-home-devicesdomestic-abuse.html

[4] Ruth Schwartz Cowan. 2011. More work for mother: the ironies of household technology from the open hearth to the microwave (nachdr. ed.). Basic Books, New York. OCLC: 838504580.

[5] Sarah J. Darby. 2018. Smart technology in the home: time for more clarity. Building Research \& Information 46, 1 (2018), 140-147. https://doi.org/10.1080/ 09613218.2017.1301707

[6] Scott Davidoff, Min Kyung Lee, Charles Yiu, John Zimmerman, and Anind K. Dey. 2006. Principles of Smart Home Control. In UbiComp 2006: Ubiquitous Computing (Lecture Notes in Computer Science), Paul Dourish and Adrian Friday (Eds.). Springer, Berlin, Heidelberg, 19-34. https://doi.org/10.1007/11853565_2

[7] Paul B. de Laat. 2019. The disciplinary power of predictive algorithms: a Foucauldian perspective. Ethics and Information Technology 21, 4 (Dec. 2019), 319-329. https://doi.org/10.1007/s10676-019-09509-y

[8] Gilles Deleuze. 1992. Postscript on the Societies of Control. October 59 (1992), 3-7. https://www.jstor.org/stable/778828

[9] A. Demeure, S. Caffiau, E. Elias, and C. Roux. 2015. Building and Using Home Automation Systems: A Field Study. In End-User Development (Lecture Notes in Computer Science), Paloma Díaz, Volkmar Pipek, Carmelo Ardito, Carlos Jensen, Ignacio Aedo, and Alexander Boden (Eds.). Springer International Publishing, Madrid, 125-140. https://doi.org/10.1007/978-3-319-18425-8_9

[10] Carole Després. 1991. The Meaning of Home: Literature Review and Directions for Future Research and Theoretical Development. Fournal of Architectural and Planning Research 8, 2 (1991), 96-115. https://www.jstor.org/stable/43029026

[11] S. M. Easterbrook, E. E. Beck, J. S. Goodlet, L. Plowman, M. Sharples, and C. C. Wood. 1993. A Survey of Empirical Studies of Conflict. In CSCW: Cooperation or Conflict?, Dan Diaper, Colston Sanger, and Steve Easterbrook (Eds.). Springer London, London, 1-68. https://doi.org/10.1007/978-1-4471-1981-4_1

[12] W. Keith Edwards and Rebecca E. Grinter. 2001. At Home with Ubiquitous Computing: Seven Challenges. In Ubicomp 2001: Ubiquitous Computing, Gerhard Goos, Juris Hartmanis, Jan van Leeuwen, Gregory D. Abowd, Barry Brumitt, and Steven Shafer (Eds.). Vol. 2201. Springer Berlin Heidelberg, Berlin, Heidelberg, 256-272. https://doi.org/10.1007/3-540-45427-6_22

[13] Uwe Flick. 2018. An introduction to qualitative research (6th edition ed.). SAGE Publications, Thousand Oaks, CA.

[14] B. J. Fogg. 2002. Persuasive Technology: Using Computers to Change What We Think and Do. Ubiquity 2002, December (Dec. 2002), 89-120. https://doi.org/10. $1145 / 764008.763957$

[15] Michel Foucault. 1995. Discipline and punish: the birth of the prison (2nd vintage books ed ed.). Vintage Books, New York.

[16] Diana Freed, Jackeline Palmer, Diana Minchala, Karen Levy, Thomas Ristenpart, and Nicola Dell. 2018. "A Stalker's Paradise": How Intimate Partner Abusers Exploit Technology. In Proceedings of the 2018 CHI Conference on Human Factors in Computing Systems - CHI '18. ACM Press, Montreal QC, Canada, 1-13. https: //doi.org/10.1145/3173574.3174241

[17] Christine Geeng and Franziska Roesner. 2019. Who's In Control?: Interactions In Multi-User Smart Homes. In Proceedings of the 2019 CHI Conference on Human Factors in Computing Systems - CHI '19. ACM Press, Glasgow, Scotland Uk, 1-13. https://doi.org/10.1145/3290605.3300498

[18] Kirsten Gram-Hanssen and Sarah J. Darby. 2018. "Home is where the smart is"? Evaluating smart home research and approaches against the concept of home. Energy Research \& Social Science 37 (March 2018), 94-101. https://doi.org/10. 1016/j.erss.2017.09.037

[19] Kevin D. Haggerty. 2006. Tear down the walls: on demolishing the panopticon. In Theorizing Surveillance. Willan, London, 23-45. https://doi.org/10.4324/ 9781843926818-7

[20] Tom Hargreaves, Richard Hauxwell-Baldwin, Mike Coleman, Charles Wilson, Lina Stankovic, Vladimir Stankovic, David Murray, Jing Liao, Tom Kane, Steven Firth, and Tarek Hassan. 2015. Smart Homes, control and energy management: how do smart home technologies influence control over energy use and domestic life?. In Paper presented at European Council for an Energy Efficient Economy (ECEEE) 2015 Summer Study. ECEEE, Toulon/Hyeres, France, 1021-1032.

[21] Tom Hargreaves and Charlie Wilson. 2013. Who uses smart home technologies? Representations of users by the smart home industry. In Paper presented at European Council for an Energy Efficient Economy (ECEEE) Summer Study on Energy Efficiency in Buildings. ECEEE, Hyeres, France, 1769-1780.

[22] Richard Harper. 2003. Inside the Smart Home: Ideas, Possibilities and Methods. In Inside the smart home, Richard Harper (Ed.). Springer, London ; New York,
$1-13$.

[23] Sampsa Hyysalo and Janne Lehenkari. 2002. Contextualizing Power in a Collaborative Design Project. In PDC 2002. Computer Professionals for Social Responsibility, Malmö, 93-104.

[24] Rikke Hagensby Jensen, Yolande Strengers, Jesper Kjeldskov, Larissa Nicholls, and Mikael B. Skov. 2018. Designing the Desirable Smart Home: A Study of Household Experiences and Energy Consumption Impacts. In Proceedings of the $2018 \mathrm{CHI}$ Conference on Human Factors in Computing Systems (CHI '18). Association for Computing Machinery, New York, NY, USA, 1-14. https://doi.org/10.1145/ 3173574.3173578

[25] Roxanne Leitão. 2019. Anticipating Smart Home Security and Privacy Threats with Survivors of Intimate Partner Abuse. In Proceedings of the 2019 on Designing Interactive Systems Conference - DIS '19. ACM Press, San Diego, CA, USA, 527-539. https://doi.org/10.1145/3322276.3322366

[26] Dan Lockton, David Harrison, and Neville A. Stanton. 2010. The Design with Intent Method: A design tool for influencing user behaviour. Applied Ergonomics 41, 3 (May 2010), 382-392. https://doi.org/10.1016/j.apergo.2009.09.001

[27] Shelley Mallett. 2004. Understanding Home: A Critical Review of the Literature. The Sociological Review 52, 1 (Feb. 2004), 62-89. https://doi.org/10.1111/j.1467954X.2004.00442.x

[28] Davit Marikyan, Savvas Papagiannidis, and Eleftherios Alamanos. 2019. A systematic review of the smart home literature: A user perspective. Technological Forecasting and Social Change 138 (Jan. 2019), 139-154. https://doi.org/10.1016/j. techfore.2018.08.015

[29] Tara Matthews, Kathleen O’Leary, Anna Turner, Manya Sleeper, Jill Palzkill Woelfer, Martin Shelton, Cori Manthorne, Elizabeth F. Churchill, and Sunny Consolvo. 2017. Stories from Survivors: Privacy \& Security Practices when Coping with Intimate Partner Abuse. In Proceedings of the 2017 CHI Conference on Human Factors in Computing Systems - CHI '17. ACM Press, Denver, Colorado, USA, 2189-2201. https://doi.org/10.1145/3025453.3025875

[30] Tobias Matzner. 2016. Beyond data as representation: The performativity of Big Data in surveillance. Surveillance \& Society 14, 2 (Sept. 2016), 197-210. https://doi.org/10.24908/ss.v14i2.5831

[31] Tobias Matzner. 2017. Opening Black Boxes Is Not Enough - Data-based Surveillance In Discipline and Punish And Today. Foucault Studies 0, 23 (Aug. 2017), 27-45. https://doi.org/10.22439/fs.v0i0.5340

[32] Sarah Mennicken and Elaine M. Huang. 2012. Hacking the Natural Habitat: An Inthe-Wild Study of Smart Homes, Their Development, and the People Who Live in Them. In Pervasive Computing (Lecture Notes in Computer Science), Judy Kay, Paul Lukowicz, Hideyuki Tokuda, Patrick Olivier, and Antonio Krüger (Eds.). Springer Berlin Heidelberg, Berlin, Heidelberg, 143-160. https://doi.org/10.1007/978-3642-31205-2_10

[33] Michael Nagenborg. 2014. Surveillance and persuasion. Ethics and Information Technology 16, 1 (March 2014), 43-49. https://doi.org/10.1007/s10676-014-9339-4

[34] Karin Niemantsverdriet, Harm van Essen, and Berry Eggen. 2017. A perspective on multi-user interaction design based on an understanding of domestic lighting conflicts. Personal and Ubiquitous Computing 21, 2 (April 2017), 371-389. https: //doi.org/10.1007/s00779-016-0998-5

[35] James Pierce. 2019. Smart Home Security Cameras and Shifting Lines of Creepiness: A Design-Led Inquiry. In Proceedings of the 2019 CHI Conference on Human Factors in Computing Systems (CHI '19). Association for Computing Machinery, New York, NY, USA, 1-14. https://doi.org/10.1145/3290605.3300275

[36] Martin Porcheron, Joel E. Fischer, Stuart Reeves, and Sarah Sharples. 2018. Voice Interfaces in Everyday Life. In Proceedings of the 2018 CHI Conference on Human Factors in Computing Systems - CHI '18. ACM Press, Montreal QC, Canada, 1-12. https://doi.org/10.1145/3173574.3174214

[37] Johan Redström and Heather Wiltse. 2018. Changing Things: the Future of Objects in a Virtual World. Bloomsbury Publishing USA, London. http://public.eblib. com/choice/publicfullrecord.aspx? $\mathrm{p}=5516511$ OCLC: 1054054026 .

[38] Jennifer A. Rode. 2010. The roles that make the domestic work. In Proceedings of the 2010 ACM conference on Computer supported cooperative work (CSCW'10). Association for Computing Machinery, New York, NY, USA, 381-390. https: //doi.org/10.1145/1718918.1718984

[39] Jennifer A. Rode and Erika Shehan Poole. 2018. Putting the gender back in digital housekeeping. In Proceedings of the 4th Conference on Gender \& IT (GenderIT '18). Association for Computing Machinery, New York, NY, USA, 79-90. https: //doi.org/10.1145/3196839.3196845

[40] Jennifer A. Rode, Eleanor F. Toye, and Alan F. Blackwell. 2004. The fuzzy felt ethnography - understanding the programming patterns of domestic appliances. Personal and Ubiquitous Computing 8, 3-4 (July 2004), 161-176. https://doi.org/ 10.1007/s00779-004-0272-0

[41] Barış Serim and Giulio Jacucci. 2019. Explicating "Implicit Interaction": An Examination of the Concept and Challenges for Research. In Proceedings of the 2019 CHI Conference on Human Factors in Computing Systems. ACM, Glasgow, 417. https://doi.org/10.1145/3290605.3300647

[42] Graham Sewell and James R. Barker. 2001. Neither good, nor bad, but dangerous: Surveillance as an ethical paradox. Ethics and Information Technology 3, 3 (Sept. 2001), 181-194. https://doi.org/10.1023/A:1012231730405 
[43] Yolande Strengers. 2013. Smart Energy Technologies in Everyday Life. Palgrave Macmillan UK, London. https://doi.org/10.1057/9781137267054

[44] Yolande Strengers, Jenny Kennedy, Paula Arcari, Larissa Nicholls, and Melissa Gregg. 2019. Protection, Productivity and Pleasure in the Smart Home: Emerging Expectations and Gendered Insights from Australian Early Adopters. In Proceedings of the 2019 CHI Conference on Human Factors in Computing Systems (CHI '19). ACM, New York, NY, USA, 645:1-645:13. https://doi.org/10.1145/3290605.3300875 event-place: Glasgow, Scotland Uk.

[45] Yolande Strengers and Larissa Nicholls. 2018. Aesthetic pleasures and gendered tech-work in the 21st-century smart home. Media International Australia 166, 1 (Feb. 2018), 70-80. https://doi.org/10.1177/1329878X17737661

[46] Leila Takayama, Caroline Pantofaru, David Robson, Bianca Soto, and Michael Barry. 2012. Making Technology Homey: Finding Sources of Satisfaction and Meaning in Home Automation. In Proceedings of the 2012 ACM Conference on Ubiquitous Computing (UbiComp '12). ACM, New York, NY, USA, 511-520. https: //doi.org/10.1145/2370216.2370292

[47] Sergio Tirado-Herrero, Larissa Nicholls, and Yolande Strengers. 2018. Smart home technologies in everyday life: do they address key energy challenges in households? Current Opinion in Environmental Sustainability 31 (April 2018), 65-70. https://doi.org/10.1016/j.cosust.2017.12.001

[48] Peter Tolmie, Andy Crabtree, Tom Rodden, James A Colley, and Ewa A Luger. 2016. "This has to be the cats" - Personal Data Legibility in Networked Sensing Systems. In Proceedings of the 19th ACM Conference on Computer-Supported Cooperative
Work \& Social Computing - CSCW'16. ACM Press, San Francisco, California, USA, 490-501. https://doi.org/10.1145/2818048.2819992

[49] Cameron Tonkinwise. 2018. 'I prefer not to'. In Undesign: critical practices at the intersection of art and design (first edition ed.), Gretchen Coombs, Gavin Sade, and Andrew McNamara (Eds.). Routledge, New York. OCLC: on1077293110.

[50] Niels van Dijk. 2010. Property, privacy and personhood in a world of ambient intelligence. Ethics and Information Technology 12, 1 (March 2010), 57-69. https: //doi.org/10.1007/s10676-009-9211-0

[51] Peter-Paul Verbeek. 2011. Moralizing technology: understanding and designing the morality of things. The University of Chicago Press, Chicago ; London.

[52] Charlie Wilson, Tom Hargreaves, and Richard Hauxwell-Baldwin. 2015. Smart Homes and Their Users: A Systematic Analysis and Key Challenges. Personal Ubiquitous Comput. 19, 2 (Feb. 2015), 463-476. https://doi.org/10.1007/s00779014-0813-0

[53] Rayoung Yang and Mark W. Newman. 2013. Learning from a Learning Thermostat: Lessons for Intelligent Systems for the Home. In Proceedings of the 2013 ACM International foint Conference on Pervasive and Ubiquitous Computing (UbiComp '13). ACM, New York, NY, USA, 93-102. https://doi.org/10.1145/2493432.2493489 event-place: Zurich, Switzerland.

[54] Yaxing Yao, Justin Reed Basdeo, Oriana Rosata Mcdonough, and Yang Wang. 2019. Privacy Perceptions and Designs of Bystanders in Smart Homes. Proc. ACM Hum.-Comput. Interact. 3, CSCW (Nov. 2019), 24. https://doi.org/10.1145/3359161 